Modeling, Identification and Control, Vol. 33, No. 2, 2012, pp. 69-86, ISSN 1890-1328

\title{
A Review on Approaches for Condition Based Maintenance in Applications with Induction Machines Located Offshore
}

\author{
J. Cibulka M.K. Ebbesen G. Hovland K.G. Robbersmyr M.R. Hansen
}

Mechatronics Group, Department of Engineering, University of Agder, N-4898 Grimstad, Norway. E-mail: \{jaroslav.cibulka, morten.k.ebbesen, geir.hovland, kjell.g.robbersmyr, michael.r.hansen\}@uia.no

\begin{abstract}
This paper presents a review of different approaches for Condition Based Maintenance (CBM) of induction machines and drive trains in offshore applications. The paper contains an overview of common failure modes, monitoring techniques, approaches for diagnostics, and an overview of typical maintenance actions. Although many papers have been written in this area before, this paper puts an emphasis on recent developments and limits the scope to induction machines and drive trains applied in applications located offshore.
\end{abstract}

Keywords: Condition monitoring; Signal processing; Diagnostics; Prognostics; Induction machine; Bearing; Gearbox; Drivetrain; Wind turbine;

\section{Introduction}

After the mid-1970's the technological advances meant that the status of the field of maintenance increased. Advancement of instrumentation and sensor techniques combined with rapidly increasing data storage capabilities, meant that new technology such as Computerized Maintenance Management Systems (CMMS) and Condition-Based Maintenance (CBM) emerged. Today, maintenance and asset management are increasingly seen as a means of strategically generating wealth, rather than being viewed as a cost to be minimized, see Arthur (2005).

Jardine et al. (2006) presented a review paper for machinery diagnostics and prognostics using CBM. As stated: The literature on machinery diagnostics and prognostics is huge and diverse primarily due to a wide variety of systems, components and parts. Hundreds of papers in this area, including theories and practical applications, appear every year in academic journals, conference proceedings and technical reports. The contributions of our paper, compared to Jardine et al. (2006), is the focus on systems using induction machines and drive trains for offshore applications as well as recent developments of models, algorithms and technologies since 2006 .

Offshore maintenance differs from land-based maintenance due to factors such as accessibility and environmental conditions. For example, in the extreme case of exposure to corrosion and sea-water flow, PalinLuc et al. (2010) demonstrates that fatigue life may be reduced by more than $70 \%$. Accessibility to perform maintenance is also reduced due to weather conditions. Tyapin et al. (2011) demonstrated that an offshore maintenance example project in the North Sea had about 4 times longer expected mean duration compared to the same maintenance performed in perfect weather conditions. These two factors (accessibility and environmental conditions) create an even higher demand for efficient maintenance strategies and technology to reduce costs compared to onshore maintenance. 
The study in this paper is limited to systems that involve an induction machine working either as a motor or a generator and that is mechanically connected to a drive train involving gear transmissions, as illustrated in Fig. 1. Section 2 contains a survey and description of typical failure modes for the considered system. Section 3 surveys typical monitoring techniques, while section 4 presents different approaches for diagnostics. Finally, section 5 presents common maintenance actions, followed by the conclusions in section 6 .

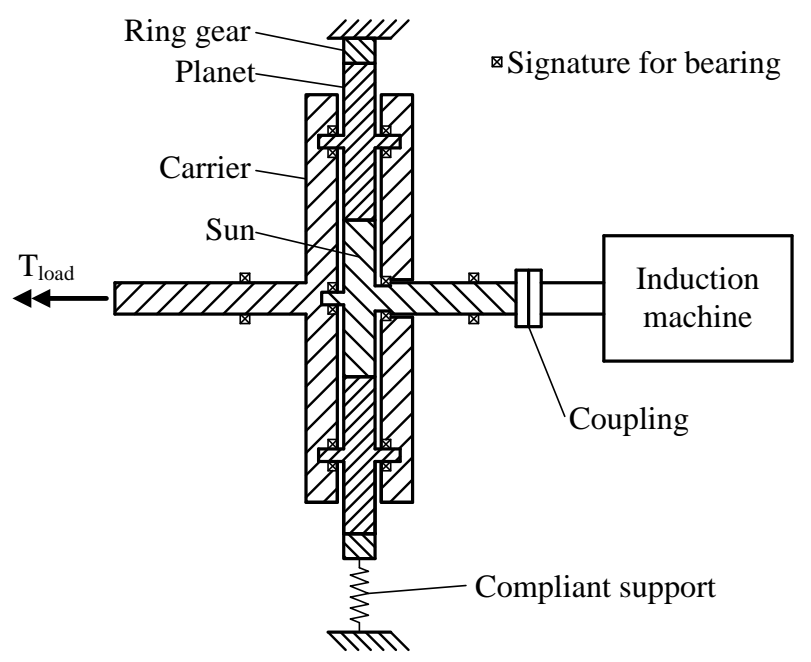

Figure 1: Considered system consisting of induction machine, gear-box and rolling-element bearings.

\section{Failure Modes}

This section surveys typical failure modes for a drive train (DT), section 2.1 and an induction machine (IM), section 2.2 .

\subsection{Drive Train}

The drive train topology in some offshore applications such as wind turbines has converged to either a gearbox between the rotor and a high speed generator or, a direct drive that avoids the gearbox while employing more complex low speed generators. The main reason for the emergence of direct drives is an expected increase in drive train reliability. Several studies, Ribrant and Bertling (2007), Musial et al. (2007), Tavner et al. (2006, 2007) and Spinato et al. (2009) report that the gear box is the main source for failures in a drive train and, subsequently, the main source for failure in the gear boxes are the bearings. Clearly, the failure mechanisms are complex and it is common to isolate the different subcomponents of a gear box with a view to identify the failure source and, as pointed out by Spinato et al. (2009) provide industry with highly asked-for statistical information. As an example, in Ribrant and Bertling (2007) the different failure sources are divided into: bearings, gears, shafts, sealings, and lubricating fluid.

However, Musial et al. (2007) stresses that this division must be done with care because different failure mechanisms may be accelerated by each other and it is important to accept the gearbox as a total system that, in general, may be designed with insufficient reliability if the dynamic load distribution is not well understood. Musial et al. (2007) describes an ongoing collaborative on gearbox reliability that emphasizes the cooperation between manufacturers of bearings, gearboxes and wind turbines with a view to improve and standardize the design process and the related load case simulations.

\subsubsection{Gearbox Failures}

The failures observed in gearboxes are typically a combination of the following five failure mechanisms, see Kar and Mohanty (2008):

- Loss of Lubrication

- Crack initiation and propagation

- Surface wear

- Surface fatigue

- Structural fatigue

Today, these mechanisms are well described in engineering textbooks on tribology or machine design, e.g. Bhushan and Gupta (1991) and Norton (2006). For clarity the fundamentals regarding these mechanisms are revisited here.

Loss of Lubrication - In general, lubrication is desirable between adjacent surfaces moving relative to one another to minimize surface wear and surface fatigue. Lubrication is obtained as a lubricating film that is several orders of magnitude smaller in thickness as compared to the characteristic dimensions of the surfaces it is dividing. The thickness of the lubricating film mainly depends on the curvature geometry of the adjacent surfaces, the viscosity of the lubricating fluid, the normal force that is transferred via the film and the velocity slip between the adjacent surfaces. The lubricating film should be substantially thicker than the height of the roughness asperities of the mating surfaces not only to avoid structural contact but also to reduce the relative variation in film thickness and thereby pressure peaks in the lubricating fluid. If the 
lubricating film is not of a sufficient thickness the surface wear and surface fatigue increase and this may be referred to as loss of lubrication. In a gearbox loss of lubrication and, subsequently, surface wear and surface fatigue, may be experienced in the bearings between the rolling elements and the raceways and in the gear meshes between the flanks of the in-contact teeth.

Crack Initiation and Propagation - If a structural component is subjected to varying loads at a sufficient intensity then cracks may initiate around or near anomalies (inclusions, microcracks, indentations etc.) within the structure where the stress level is high. Therefore, crack initiation is often observed on the surface of structures because of the combination of high stresses and many anomalies. If the loading conditions continue then the crack initiation will be followed by a crack propagation that in turn may lead to rupture where parts of the structure break off or, indeed, the entire structure ruptures. The combination of these three phenomena: crack initiation, crack propagation and rupture is fatigue. In gearbox design steel in different variations is the dominant material. In steel and other ductile materials the crack propagation is normally a continuous process where small increments in crack length are experienced within certain intervals depending on the intensity of the load on the crack tip. In less ductile materials the crack propagation is a singular event directly followed by rupture. In steel, the rupture is experienced when the crack propagation has generated a structure where the peak values of the varying load causes nominal stresses above the ultimate strength. It is possible using the combined theoretical and experimental findings within the area of fatigue to design machines where both initiation and propagation of cracks are either avoided (infinite life) or controlled (specified life) with a certain reliability. This is done by ensuring that load variations on the individual components stay below certain threshold values. The main difficulty is to estimate or simulate the correct loading variations on the components because this often involve complex dynamic models in combination with unknown external loading. For machined parts such as gears, shafts and bearings the fatigue encompasses both initiation and propagation as opposed to welded structures that are equipped with cracks via manufacturing and therefore must be designed to avoid or control propagation.

Surface Wear - Surface wear may be divided into several sub categories. Typically they are referred to as abrasion, adhesion, corrosion and erosion. They are all characterized by a steady continuous loss of material from one or both of the mating surfaces. Also, they may include a third party in the shape of free particles that travel within the lubrication fluid. In the closed environment of a gearbox this is typically debris caused by the particles that are removed from the gears and roller bearings because of surface wear and surface fatigue.

Surface Fatigue - Surface fatigue occurs near the surface of a structural part subjected to varying loads. Analytical results based on Hertzian theory reveal that two surfaces in rolling contact will have a stress distribution where the highest shear stress is located a certain distance below the surface. Hence, crack initiation will happen below the surface and the crack will propagate towards the surface resulting in small particles breaking off. In literature this is referred to as pitting or spalling, where the latter is reserved for severe pitting where other failure mechanisms have become active. In practice, pure Hertzian pitting is seldomly encountered, because most surfaces have a tendency to slide on each other introducing a more complex load pattern that together with the higher concentration of anomalies on the surface means that the surface fatigue crack initiation may just as well be on the surface. Surface fatigue may be thought of as special type of erosive surface wear but with a distinctly discontinuous behaviour since the particle break off, in general, happens in larger intervals of load variations.

Structural Fatigue - Structural fatigue is fatigue resulting in rupture of entire components or substantial subcomponents. In gearboxes this is typically the rupture of an entire gear tooth with a crack propagating from the surface of the gear tooth through the base of the tooth. Alternatively, but less common, it is the rupture of an entire shaft with a crack propagating from areas of stress concentration typically encountered in the part of the shaft geometry that facilitates bearing and gear mounting.

It should be noted that the above failure mechanisms are intimately correlated in practice and that they will have a tendency to accelerate each other: too high temperature in gearbox $\rightarrow$ lower fluid viscosity $\rightarrow$ loss of lubrication $\rightarrow$ more friction $\rightarrow$ higher temperatures, or: too high impact load on bearing $\rightarrow$ surface wear/fatigue $\rightarrow$ lack of geometry smoothness $\rightarrow$ increase impact loading. An almost infinite number of such examples can be established, and they will, in general, have lack of insight into the actual loading conditions as the common denominator Norton (2006).

\subsubsection{Bearing Failure}

Failure of a rolling-element bearing caused by a static load is defined by the size of permanent deformations on the rolling-elements. The limiting value is defined to be a deformation with the depth of $1 \mathrm{e}-4$ times the diameter of the rolling-element. Larger deformations cause an increased level of noise and vibration and leads to 
premature fatigue failure.

In the case with sufficient clean lubrication the failure will be surface fatigue in either the balls/rollers or the raceways but usually first in one of the two raceways. The fatigue will show as pitting in the surface of the raceway. The pitting will cause noise and vibration when the rolling elements pass the pit. If the bearing is run beyond the first warning then the first pit may grow and the damage may also include fracturing one or more rolling-elements Norton (2006). Compared to the case with insufficient lubrication the force transmitted between the ball/roller and the raceway is distributed over a larger area reducing the stress level, FAG (1986).

\subsubsection{Tribocorrosion}

Mechanical parts in offshore drivetrain applications, especially bearings, are subject to corrosion and wear, i.e. often prone to tribocorrosion. Landolt (2006) defined tribocorrosion as a material degradation process, concerning the irreversible transformation of materials or of their function as a result of simultaneous mechanical (wear) and chemical/electrochemical interactions (corrosion) between surfaces in relative motion.

Other tribocorrosion phenomena are fretting and erosion-corrosion. Fretting corrosion is caused by small amplitude vibrations between contacting surfaces, followed by oxidation of both the metallic debris and the exposed metallic surfaces. Since the oxidized debris is much harder than the surface, it acts as an abrasive agent and increases the rate of both fretting corrosion and false brinelling. Fretting corrosion decreases fatigue strength (fretting fatigue), resulting in fatigue cracks and its propagation.

Erosion-corrosion is studied by Sasaki and Bursteina (2000) as a mechanical and chemical effect caused by impacting particles or fluids, which erode a solid surface by abrasion, chipping or fatigue while simultaneously the surface corrodes.

Tribocorrosion is a critical phenomenon even for corrosion resistant metals (passive metals). Landolt (2007) studied the corrosion resistance, based on selfgenerating thin oxide surface film (passive film), and film deterioration caused by a continuous and extensive rubbing. The underlying metal will corrode before the protective passive film is reestablished.

The total material loss due to tribocorrosion will be much higher than the sum of wear and corrosion, i.e. tribocorrosion rate is not the addition of the wear rate and the corrosion rate. The tribocorrosion process is strongly affected by synergistic and antagonistic effects between mechanical and chemical mechanisms. Mischler and Ponthiaux (2001) studied the synergistic ef- fect of wear and corrosion, providing a significant contribution to the total material loss.

von der Ohe et al. (2010) extended the study of the tribocorrosion synergistic effect by applying static and cyclic tensile loading. Two multi degradation theories, describing the interaction of applied corrosion fatigue and stress corrosion cracking mechanisms were presented. A mathematical model of piston rod multidegradation was presented as a case study of a tribocorrosion situation in an offshore application. It consists of hydraulic cylinder piston rods providing tensioning of drilling risers in the splash zone on board offshore drilling vessels.

Wood et al. (2010) presented the tribology of three offshore marine renewable energy conversion systems offshore wind turbines, tidal and wave machines. The study included lubrication, contamination, bearing and gearbox issues, cavitation erosion, tribocorrosion, condition monitoring and tribological design constraints associated with tribological components. Kawazoe and Ura (2001) performed experiments in order to evaluate corrosive wear resistance and to clarify the damage behaviour of materials used for sliding parts (bearings) exposed to seawater.

SrinivasaPai et al. (2008) presented modelling of microabrasion-corrosion processes, by using an artificial neural network (ANN), multilayer perceptron neural network (MLPNN) and resource allocation network (RAN).

\subsection{Induction Machine}

The survey paper Thorsen and Dalva (1995) covering the Norwegian offshore industry included approximately 2600 induction machines. The failure distribution is shown in Fig. 2.

The following subsections describe some of the most typical failure modes for an IM in more detail.

\subsubsection{Bearing failure}

Bearing faults represent the most frequent failure in IM. Foster (2009) indicates fluting as a typical bearing fault in electric drivetrain. Fluting is caused by prolonged passage of relatively small electric current, usually due to current leakage, e.g. from shorted lamination, or eddy currents. When static electricity is emitting from charged drivetrain parts, current leaks through a shaft into the bearing and to the ground. Current bridges the lubrication film between rolling element and raceways. Microscopic arcing produces localized and extreme temperatures that melt the crossover point. Such a prolonged electrical erosion results in fluting pattern of accumulated microscopic pits. Flutes are deep, exhibit noise, vibration 


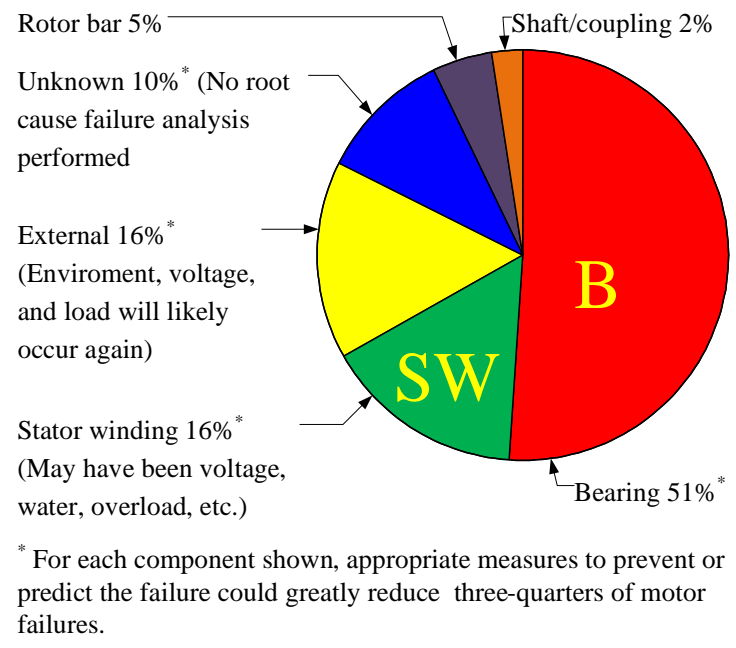

Figure 2: Failure mode distribution for induction machine.

and lead to fatigue.

\subsubsection{Insulation Breakdown}

The second most frequent failure of IM is stator windings (SW) insulation breakdown. There are three types of SW insulation: Phase-to-Phase (primary insulation system), Turn-to-Turn (secondary insulation system) and Phase-to-Ground (Ground-Wall) insulation.

J. Geiman (2007) presented a case study, where the surge tests have proven that $80 \%$ of all SW insulation failures originate from a weak turn-to-turn insulation. Stone et al. (2004) stated the main failure root causes of SW insulation deterioration: mechanical stress, contamination, electrical and thermal stress.

The main causes for insulation failure due to mechanical stresses are coil movement and vibration, i.e. loose SW. Loose SW is causing abrasion of wire insulation leading to shorted turns and grounded circuits. Coil vibrations are proportional to the square of the motor current and peak during startup. Another cause of mechanical insulation failure is rotor strike, caused by bearing failures, shaft deflection and rotor-stator eccentricity.

Bethel (1999) studied rotor-stator eccentricity as an unevenly distributed air gap, i.e. magnetic fields. These magnetic imbalances cause stator windings movement, resulting in winding failure, and electrically induced vibration and consequent bearing failure. Static eccentricity is a result of soft foot or warped bases, and represents a directional source of high vibrations. Dynamic eccentricity causes rotating airgap variations and it is a pulsating vibration source.

Chemical contamination, moisture and particles in the

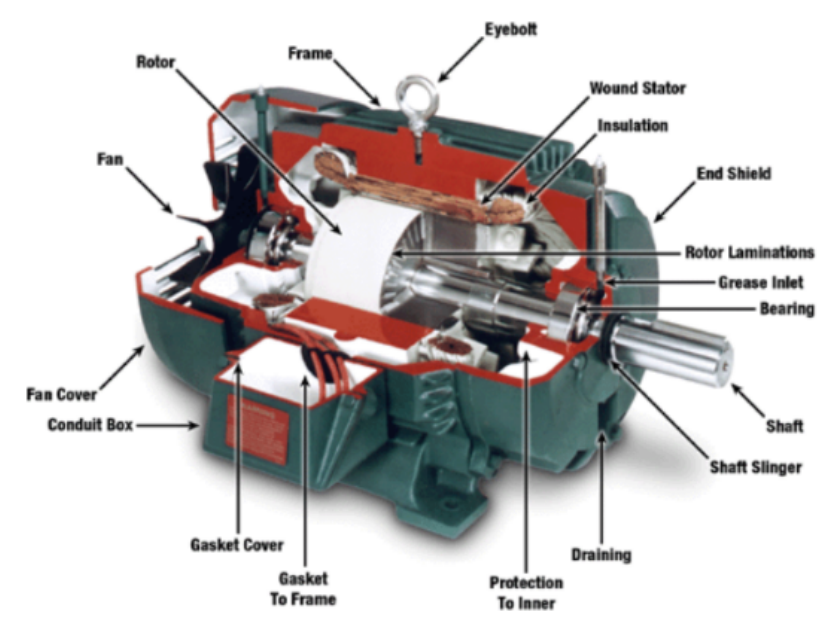

Figure 3: Typical construction of an induction machine.

motor lead to insulation deterioration, shorts, reduction of heat dissipation and bearing failure. Electrical stress is presented by voltage surges, which are typically caused by VFD (variable frequency drive) start/stop switching and lightning strikes.

Thermal overloading accelerates insulation deterioration. The standard NEMA (2010) states that a $10^{\circ} \mathrm{C}$ increase will reduce the SW insulation life time by $50 \%$. Thermal overloading in one phase is caused by voltage variations due to unbalanced loads on the power source. Thermal deterioration in all phases is caused by under/over-voltage and very high currents, due to a locked rotor and excessive starts/reversals. 3.5\% voltage unbalance will increase the temperature by $25 \%$ and $1 \%$ voltage unbalance may result in a $6-10 \%$ current unbalance.

\subsubsection{Loose or Cracked Rotor Bars}

Broken, cracked or corroded rotor bars are other frequent failures in IM. Thomson and Fenger (2001) and Nandi et al. (2005) stated typical causes of a broken rotor bar: 1) Frequent starting duty cycles under load, resulting in magnetic, mechanical and thermal stress (high starting current heats up the rotor bar); 2) Pulsating mechanical loads, from shaft torques and centrifugal forces; 3) Mechanical stress, due to loose laminations or bearing failure; 4) Environmental stresses - contamination, chemicals or moisture; and 5) Imperfect manufactured rotor cage, contains residual stresses. 


\section{Monitoring}

This section surveys typical condition monitoring techniques for induction machine-gearbox drivetrains respectively, vibration, section 3.1, current, flux, section 3.2, and fluid parameters monitoring, section 3.3.

\subsection{Vibration}

Vibration signals are the most common waveform data in Condition Monitoring (CM). Zipp (2010) introduced an intelligent vibration monitoring for wind plants - a vibration data acquisition system consisted of embedded accelerometers, high speed digital signal converters and wireless Ethernet network.

A typical monitoring method for roller bearings is Hanning-FFT (H-FFT analysis), creating an enveloping of the target frequency, i.e. enveloped spectrum. Bearings are typically monitored at specific small-band damage frequencies (narrow-band monitoring) according to the geometry of their inner race, outer race, and rolling elements. Gear mesh frequency is monitored at narrow- and side-band with 2nd and 3rd harmonics, and evaluated to detect gear wear and defects.

Ellingssen et al. (2006) reviewed condition monitoring techniques in offshore, such as vibration monitoring on heavy rotating equipment. Mendel et al. (2009) presented a vibration analysis technique for fault detection in rotating machines used in offshore oil rigs. Rolling element bearing defects inside a motor pump are the subject of study by means of signal processing and pattern recognition techniques. Liyanage (2008) presented online remote vibration monitoring of critical offshore machinery by use of wireless advanced sensors and webenabled solutions.

Multiple sensor data fusion techniques are now commonly in use due to the inherent superiority in taking advantage of mutual information from multiple sensors. Data fusion techniques are used at the sensor level to ensure data quality and provide for sensor self check. Reichard et al. (2000) described the system architecture, data fusion, and classification algorithms employed in a distributed, wireless bearing and gear health monitoring system. Data fusion techniques such as Dempster-Shafer fusion, Bayesian inference, fuzzy-logic inference, neural network fusion and simple weighting/voting, are usually applied in gearbox vibration monitoring. Inappropriate oil and vibration features can be determined by sensor data fusion, in order to improve gearbox fault diagnostics and prognostics.

\subsection{Current and Flux}

As it is stated in section 2.2.2, the second most frequent failure in IM is stator insulation failures. Siddique et al. (2005) presented a review of monitoring methods to determine the stator insulation condition. Standards for stator insulation testing are stated in NEMA (2010) and Stone (2005).

Since $80 \%$ of insulation faults begin with weak turn-toturn (T-T) insulation, the monitoring of the turn insulation's condition is of special interest. Grubic et al. (2008) presented a survey of methodes to monitor and detect $\mathrm{T}-\mathrm{T}$ insulation faults.

Offline tests of a disconnected IM are direct and accurate. Typical offline tests are: winding resistance test (DC conductivity test), insulation resistance test (Megohm test), polarization index test, DC high potential test (DC HiPot), AC high potential test (AC HiPot), offline-partial-discharge test Kim and Ju (2002), dissipation-factor test, inductive-impedance test and the surge test.

It has been proven that the surge test is clearly the best offline monitoring method, since it is not only capable of detecting a T-T fault, but also to measure the integrity (deterioration) of the turn insulation. Wiedenbrug et al. (2003) described the surge test and turn insulation deterioration. A surge test is based on high voltage impulse applied between the turns. According to Lenz's Law, the voltage between the adjacent winding loops will be induced. If the voltage is too high, the arc will be developed and detected by observing the impulse response, i.e. surge waveform, where change in the frequency and the magnitude indicates T-T insulation fault.

Online monitoring techniques often require the installation of additional sensors, e.g. magnetic flux and temperature. However, methods utilizing quantities that are already measured in a system are preferred. Lu et al. (2006) presented such online methods, utilizing electrical signatures, i.e. the IM's stator current and voltage from the terminals. In addition, nonintrusive and sensorless, model-based approaches can be a cost-efficient alternative.

Typical online tests are: temperature monitoring Gao et al. (2008); tagging compound and particle (smoke) detector Stone (2002); leakage currents Lee et al. (2006); sequence components - negative sequence current Albizu et al. (2006), - sequence impedance matrix Lee et al. (2003), - zero sequence voltage Cash et al. (1998); signature analysis - axial leakage flux Assaf et al. (2004), -current signature analysis Gentile et al. (2003), -vibration signature analysis Trutt et al. (2002); partial discharge Stone and Kapler (1998) and high frequency impedance test.

High frequency impedance test, also called T-T capaci- 
tance test, is a promising online approach, since it is the only method capable to monitor and diagnose the turn insulation deterioration before a failure occurs. The test principle is presented by Werynski et al. (2006), and is based on observing and detecting changes in the high frequency response of IM, i.e. T-T capacitance (broadband impedance spectrum). By using the magnetic probe (search coil), the flux, resulted from small high freguency signals injected into the SW, is measured. The phase lag change indicates change of resonance frequency, i.e. T-T capacitance, which means insulation deterioration.

Grubic et al. (2008) proposed a need for a new online $\mathrm{T}$-T insulation monitoring approach - an online surge test, based on offline surge testing principles.

\subsection{Fluid Parameters}

Contamination is the most common and serious failure source. Therefore, lubrication oil testing and analysis is one of the most popular condition monitoring (CM) techniques for rotating machinery maintenance and fault diagnosis. Oil analysis consists of property, contamination and wear debris analysis (WDA).

Property analysis, also known as lubricant degradation analysis, is based on physical (temperature, kinematic viscosity, mechanical impurities) and chemical characteristics (composition, metal inclusions, water content, acidity, density).

Contamination analysis determines cleanliness level. It is based on a particle quantifier index ( $\mathrm{PQ}$ index or contaminate index), which is a measure of the amount and concentration of entrained wear debris particles in the lubricant oil. $\mathrm{PQ}$ index increases as viscosity decreases. Another indicator of actual contamination is NAS (National Aerospace Standard) Level.

WDA is the most accurate oil analysis strategy. WDA includes the study of debris factors: quantity, size, morphology (shape), wear mechanisms, chemical form, colour and other factors to assess the wear state and wear source. Roylance et al. (2000) introduced 6 main types of wear particles: rubbing, spherical, laminar, cutting, fatigue chunk and severe sliding particles.

Raadnui and Kleesuwan (2005) proposed scheduled offline oil sampling for laboratory analysis, based on ferrography and spectroscopy, as the dominating techniques for oil CM. Today there exists a variety of forms of oil based CM methods and techniques to check the volume and nature of foreign particles in oil for equipment health monitoring. There are spectrometric (Spectrographic, Spectroscopy) oil analysis, scan electron microscopy/energy dispersive X-ray analysis, energy dispersive X-ray fluorescent, low powered optical microscopy, and ferrous debris quantification (Ferrography).
Spectrographic analysis, based on atomic emission spectrometry (Spectroscopy), are optical methods studying the spectra of chemical elements in debris particles. Carter et al. (2010) reviewed spectroscopic methods and indicated laser induced breakdown spectroscopy (LIBS) as the most commonly used detection technique for ferrous metals as debris particles in lubrication oil. Energy dispersive X-Ray Florescence technology is used to detect iron and copper particles.

Ferrography is a CM technique, where a microscopic examination and analysis of the ferrous wear particles in lubrication oil is done. Myshkin et al. (2003) introduced optical ferroanalyzer in addition to ferrograph, in order to estimate the total contamination of oil.

\section{Oil analysis in order to detect Gear Damage}

Dempsey (2001) reported experiments, proving that oil debris data combined with fuzzy logic analysis techniques is a good predictor of pitting damage on spur gears. Rodriguez et al. (2008) used latent nestling method (colored Petri Nets) to diagnose a lubrication and cooling system for wind turbine gearboxes. A timedomain analysis has been applied, based on multivariate statistical technique, known as principal component analysis (PCA), to spectroscopic data in order to monitor the condition of a lubricant in gearboxes.

\section{Bearing Damage caused by improper lubrication}

High frequencies (ultrasonic) are generated due to poor lubrication in bearings, and can be detected by acoustic and ultrasonic sensors (Doppler Effect principle). Wright (2008) presented an acoustic monitoring technique to determine when to lubricate and how much lubrication a bearing needs. Zhang and Drinkwater (2006) presented ultrasonic monitoring of lubricant film failure in a ball bearing.

Despite the fact, that vibration and WDA are the two main and most popular CM techniques for machinery maintenance and fault diagnosis, they are capable to find only about $40 \%$ of the faults when used separately, Peng and Kessissoglou (2003). Practical experience has shown that integrating (combining) these two techniques provide a more reliable and effective maintenance program. Gao et al. (2007) integrated oil and vibration monitoring by using the information fusion method, the Dempster-Shafer theory for correlative evidence (D-S theory of evidence), in order to improve diagnosis. Troyer and Williamson (1999) concluded that correlation between the oil and vibration analysis techniques is generally good for both bearing and gear tooth fracture faults. Peng et al. (2005) studied the effect of particles in gearbox lubricants, using WDA and vibration CM techniques, and investigated the correlation between them. Ebersbach et al. (2006) investigated effectiveness of combining vibration anal- 
ysis and WDA techniques on gearboxes. WDA was performed by a numerical approach (descriptors), facilitated by the use of a laser scanning confocal microscope (LSCM). Dempsey (2000) presented comparison of vibration and online WDA, in order to detect pitting damage on spur gears. Tan et al. (2005) presented correlation of vibration, acoustic emission (AE), and spectrometric oil analysis for spur gear fault (pitting) diagnosis.

Edmonds et al. (2000) reported a method using acoustics (high-frequency impulse), instead of chip detectors (particle counter), for detecting precursor wear debris particles as small as $3 \mu \mathrm{m}$, in order to predict wear by wear trend analysis. Murali et al. (2008) presented a promising online oil debris detection method based on a microfluidic device. Particles detection and counting is based on the capacitance Coulter counting principle, where the capacitance change is caused by the presence of a metal particle.

\section{Diagnostics}

A review on machinery diagnostics and prognostics implementing CBM was given in Jardine et al. (2006). This section contains a survey of recent techniques results since 2006 and also older work not covered in Jardine et al. (2006). The section is organised into modelbased diagnostics, section 4.1 and diagnostics based on signal processing, section 4.2.

\subsection{Model-Based}

The models used for diagnostics are categorised as physics-based (4.1.1) and statistical (4.1.2).

\subsubsection{Physics-Based Models}

In horizontally mounted gearboxes (for example in wind turbines) gravity excitation is a fundamental vibration source. Planetary gears are showing both tooth wedging and planet bearing failures. Guo and Parker (2010) show that gravity is the dominant excitation source for tooth wedging. Larsen et al. (2003), Rasmussen et al. (2004) and Hansen et al. (2010) describe bearing failures and the connection to tooth wedging. Ambarisha and Parker (2007) predicted the existence of tooth contact loss and other nonlinear phenomena in a planetary gear system using finite element and lumped-parameter models.

Guo and Parker (2010) presented dynamic modeling and analysis of a typical planetary gear representative for a geartrain by introducing tooth wedging, tooth contact loss, and bearing clearance into a lumpedparameter model. The two-dimensional lumped- parameter model is expanded to include tooth separation, back-side contact, tooth wedging (or tight mesh), and bearing clearances. Tooth wedging, through enlarged forces, increases the risk of bearing failures.

Guo and Parker (2010) extended a model presented in Lin and Parker (1999). The extended two-dimensional model contains the carrier, the ring, the sun and the planets, each being rigid bodies having two translational and one rotational degrees of freedom. The extended model has a total of $3(\mathrm{~N}+3)$ degrees of freedom, where $\mathrm{N}$ is the number of planets.

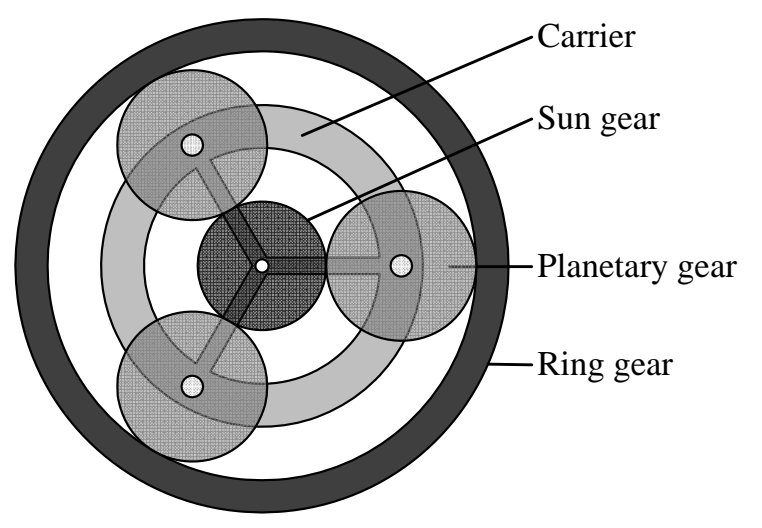

Figure 4: Typical planetary gear with three planets.

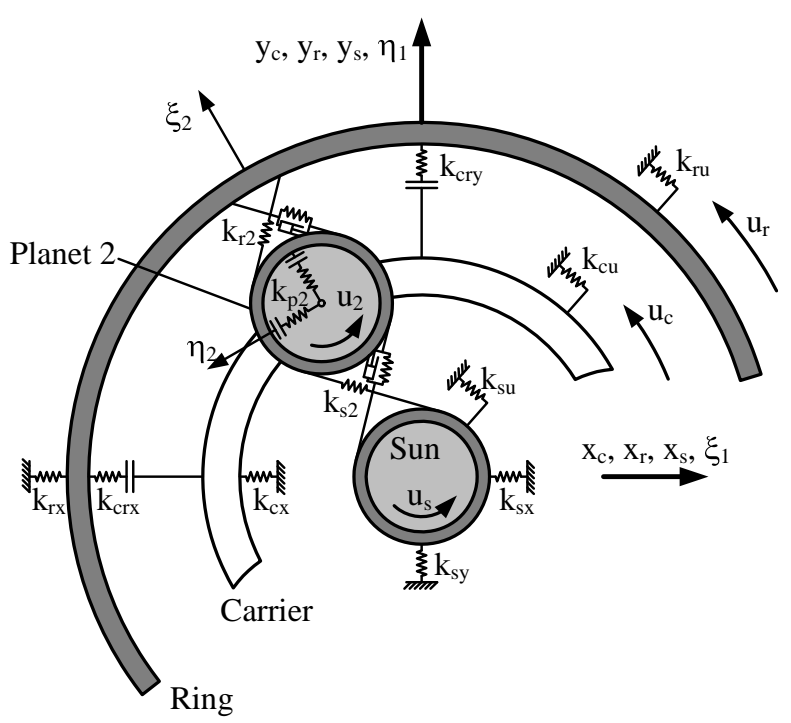

Figure 5: Lumped-parameter model as in Guo and Parker (2010).

In the extended model, shown in Figs. 4 and 5, the bearings are modeled as springs with clearance nonlinearity, and gear meshes are modeled as nonlinear 
lumped springs that act only when the teeth are in contact. The translational displacements are assigned to the carrier, the ring and the sun with respect to the basis that is fixed to the carrier. The rotational and translational displacements of the planets are with respect to the basis rotating with the carrier and oriented for each planet. The tooth contact model captures four possible situations: 1) drive-side tooth contact, 2) back-side tooth contact, 3) no contact and 4) tooth wedging. Drive-side tooth contact is modeled by a mesh stiffness along the line of action, see Fig. 6 .

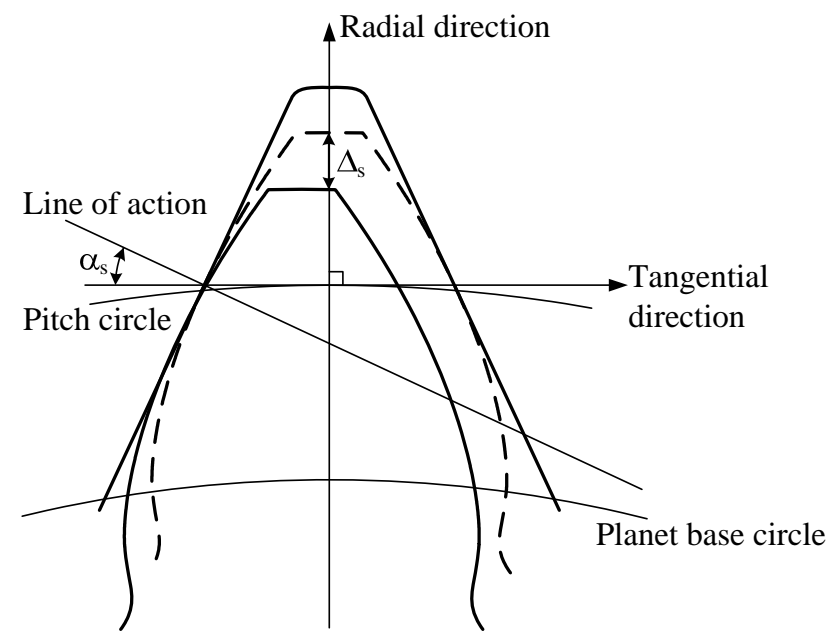

Figure 6: The tooth positions for drive-side contact (solid line) and tooth wedging (dashed line), see Guo and Parker (2010).

Fluctuating mesh stiffness as the number of teeth in contact changes periodically between one and two pairs at each mesh is an important vibration source that can cause parametric instability in planetary gears Lin and Parker (2002). The parametric excitation is introduced through time-varying mesh stiffnesses at the S-P (SunPlanet) and R-P (Ring-Planet) meshes. Tooth wedging occurs when the relative radial motion of two mating gears exceeds a specified tooth radial gap $\Delta \mathrm{s}$. The tooth radial gap is the radial clearance between a pair of mating gears when they move radially relative to each other. The gap is a specified quantity estimated from the backlash and tooth geometry.

The excitations consist of gravity, external applied loads, and the parametric excitations from fluctuating gear mesh stiffnesses. In well-lubricated gears the friction is usually small and in this model the friction is modeled through modal damping.

The linear bearings or fixed supports without clearance are modeled as one torsional and two translational springs. The nonlinear bearings are modeled as cir- cumferentially distributed radial springs with uniform clearances, see Fig. 7.

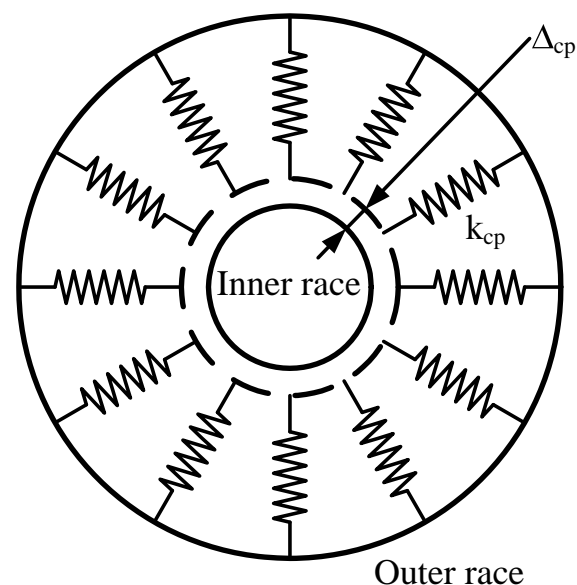

Figure 7: Bearing Model as in Guo and Parker (2010).

Forces develop only when the relative displacement between the connected bodies exceeds a specified clearance, and the direction is determined by a contact angle and the direction of relative motion between the carrier and the planet. The model developed by Guo and Parker (2010) could be used in an observer for system identification and diagnostics. An example of such a model-based diagnostics framework is presented by Choux et al. (Jan. 23-26, 2012, Nevada).

Tallam et al. (2002) introduced a physics-based IM model with T-T fault. Lee et al. (2002) introduced model-based stator resistance estimation for IM SW temperature monitoring.

\subsubsection{Statistical Models}

Jones et al. (2010) applied Bayesian network modelling to model the various parameters responsible for the failure rate of a system. The use of Bayesian network modelling allows certain influencing events to be considered which can affect parameters relating to the failure-rate of a system. Bayesian network modelling also allows these influencing events to change and update depending on the influencing data available at any given time, thus changing the failure rate or probability of failure.

Garnero et al. (1998) presented an approach for optimization of inspection intervals for the motor-pump set of an auxiliary feedwater system in a nuclear plant. The paper focused on plain hydrodynamic bearings and thrusts. The authors applied Monte Carlo simulations to study wear induced by repeated starts and stoppings, wear due to the presence of particles in the lubricating oil, and effects of oil pump failures in the lubrication system. The analysis variable used was the 
babbitt thickness variation (antifriction material).

\subsection{Signal Processing}

The signal-processing-based approaches for diagnostics considered are the Fourier Transform (4.2.1) and Wavelets (4.2.4).

\subsubsection{Fourier Transform}

FFT analysis is useful tool for rotor fault detection of IM. Frequency filters, envelope analysis and Hilbert transformation are fault detection methodes for bearings.

Power cepstrum, another useful spectrum for signal processing, is defined as the inverse Fourier transform of the logarithmic power spectrum. Power cepstrum has the capability to detect harmonics and sideband patterns in a power spectrum, especially in bearing faults.

High-order spectrum (statistics), i.e., bispectrum or trispectrum, can provide more diagnostic information than power spectrum for non-Gaussian signals. Bispectrum analysis has application in gears, bearings, induction machines and rotating machines.

Estimation of power spectrum is based on parametric models for the signal. Autoregressive Model (AR) and Autoregressive Moving Average Model (ARMA), are the two most commonly used models to estimate parametric spectra in machinery fault diagnostics, especially bearing faults.

Although the FFT is the most common signal processing method for diagnostics, it has its limitations. The FFT is reasonable only for stationary signals without transient conditions. For example, the transient conditions are presented in the variable speed drives, within offshore wind turbine or drilling machine, where the supply frequency of the stator current varies according to speed. In this case the FFT of the stator current may not be capable to describe the frequency characteristics in time and to distinguish amplitude modulation or phase modulation. Hence, the FFT as such may not be capable to clearly determine the failure source. For such non-stationary conditions, the time-frequency signal analysis is required, e.g. Instantaneous Frequency, Pseudo Wigner Distribution or Wavelets.

\subsubsection{Instantaneous Frequency}

For a definition of the Instantaneous Frequency (IF), the complex analytical monocomponent signal $z(t)$ is considered and obtained via the Hilbert transform $H\{$.$\} of the original measured real signal x(t)$, Flandrin (1999): $z(t)=x(t)+j H x(t)=a(t) e^{j \varphi(t)}$, where $\varphi(t)$ is the instantaneous phase and $a(t)$ is the instantaneous amplitude. The phase information of a complex signal is retrieved considering its argument. The IF $f_{i}(t)$ is defined by the time derivation of the phase $\varphi(t)$, Boashash (2003): $f_{i}(t)=\frac{1}{2 \pi} \frac{d}{d t} \varphi(t)$. The IF is used for phase modulation detection, since amplitude modulation is not reflected.

\subsubsection{Pseudo Wigner Distribution}

The Wigner Distribution (WD) provides a signal representation with respect to time and frequency which can be interpreted as a distribution of the signal energy. The major property of the WD is its focus on the IF in the case of a linear frequency modulation, typical for adjustable electric drives. The Pseudo Wigner Distribution (PWD) is a smoothed and windowed version of the WD. The interference terms are reduced by introducing an additional smoothing window function $p(\tau)$, Flandrin (1999). The PWD is defined as the Fourier transform of a kernel, $K_{x}(\tau, t)=$ $x\left(t+\frac{\tau}{2}\right) x^{*}\left(t-\frac{\tau}{2}\right)$, multiplied with window function: $P W_{x}(t, f)=\mathfrak{F}_{\tau \rightarrow f}\left\{p(\tau) K_{x}(\tau, t)\right\}$.

Blödt et al. (2010) presented on-line fault indicators for variable speed drive with induction motor, based on IF estimation and the PWD. Such fault indicators are able to detect and distinguish amplitude modulation and phase modulation of the stator current frequency, at specific fault-related frequencies. Amplitude modulation indicates rotor eccentricity, typically related to misalignment faults, whereas phase modulation indicates torque oscillations, typically related to bearing faults.

\subsubsection{Wavelets}

A review on the applications of the continuous wavelet transform (CWT) in machine CM and fault diagnostics was given in Peng and Chu (2004). In this section new and additional results are presented.

Fault diagnostics of offshore applications employing induction machines has been studied in Watson et al. (2010). An alternative approach to conventional sensor-based vibration monitoring has been presented by means of monitoring the power output signal of a wind turbine generator and processing the data using a Morlet CWT in order to extract the magnitude of fault-related frequency components. By this approach, the shaft misalignment has been detected three months prior to consequent bearing fault occurred. Another similar study about CWT analysis of a power signal has been presented in Wiggelinkhuizen et al. (2008). Concerning other bearing fault diagnostics, CWT is often combined with FFT. A signal de-noising process was presented by Junsheng et al. (2005), Yang and Ren 
(2004), and Lin et al. (2004), with focus on bearing and gear faults. Another wind turbine fault diagnosis method was presented in Tang et al. (2010), where Morlet CWT is employed to filter useless noise in the raw vibration signals and extract the gear fault feature. Other de-noising techniques based on CWT is presented by Loutridis (2006).

CWT, i.e. wavelet polar maps, are used for gear fault diagnostics, to display wavelet amplitude and phase.

The detection of broken rotor bars in induction machines by using CWT analysis of current waveforms was presented in Zhang et al. (2003), Antonino-Daviu et al. (2006), Riera-Guasp et al. (2008) and Briz et al. (2008).

\section{Maintenance Actions}

Maintenance Action (MA) is basic maintenance intervention, an elementary task carried out by a technician. MAs are routine maintenance actions (lubrication), inspections (minor repairs) and major overhauls. Kothamasu et al. (2006) reviewed MA techniques with focus on improving reliability by monitoring and predicting machine health. The following sections present different approaches to decide when to do maintenance and what type of activity to carry out.

\subsection{Alignment and Balancing}

Alignment and Balancing are the essential MAs for rotating machinery. Very important MA is alignment setting, since misalignment is a root failure cause, responsible for over $50 \%$ machinery faults, as stated by Mobius (2008). By adding extra load and stress, misalignment destroys bearings, seals, couplings and shafts. In practice, misalignment is a combination of angular (gap) and offset (parallel) deviations, where rotational centerlines are not collinear. Misalignment causes are: soft foundation, soft foot, looseness, runout, inaccurate assembly and temperature effects (thermal expansion/contraction). Cocked bearing is a form of misalignment, caused by wrong thermal/press fitting. Precision alignment significantly increases lifetime, by using tools, such as dial indicators, laser alignment tools and tolerances tools. A misalignment tolerance guide and charts/tables, based on speed, are presented in Piotrowski (2007).

Balancing is another important MA, since mass unbalance is a great source of vibration. The vibration level due to unbalance will increase in proportion to the square of the speed, whereas vibration due to misalignment will not change. Machinery balancing requires amplitude and phase readings, represented by vectors on polar plot. By adding trial weight and then correction weight (trim weight for refinement), the mass balance is achieved.

Offshore structures have modular design, i.e. components are pre-assembled into the modules onshore. Within assembly, all rotating parts are aligned and balanced, typically by using laser alignment and tolerance tools. Modules are then transported and installed on the offshore destination, typically an oil rig or a wind turbine. Onshore module-based alignment and mass balancing therefore allows easier and quicker offshore marine operations.

\subsection{Precautionary Maintenance Actions}

The degradation (failure occurrence) can be controlled through preventive and precautionary maintenance actions (PMAs), such as vibration monitoring (3.1), current/flux (3.2) and oil analysis (3.3) as well as design adjustments. PMAs reduce the failure probability and avoid the failure consequences.

PMAs are based on real-time CM and prediction of stochastic behaviours. Measurable condition signals the failure probability. Certain performance indices are continuously monitored. Whenever an index value crosses some predefined threshold, an alarm is activated and MAs are performed, often in combination with an FFT analysis (4.2.1). Alarms are classified according to severity level. Each severity class specifies a lead time until recommended service MA. Genetic algorithms and Monte-Carlo simulations are used to model continuously monitored deteriorating systems, and thereby to find the optimal degradation thresholds of maintenance intervention.

PMAs form the basis for a predictive maintenance strategy, known as CBM. CBM is a set of PMAs, which enable detecting, analyzing and correcting a problem before a failure occurs. CBM is a methodology that strives to identify incipient faults before they become critical, to enable more accurate planning of PMAs.

\subsection{Model-Based Maintenance}

To evaluate different MAs, mathematical models are needed for the failure of assets and the effect of maintenance on these failures. Rigdon and Basu (2000) presented two level modeling - system and component. Lin et al. (2002) developed a simulation model for field service with integrated CBM actions.

\subsection{Optimal Maintenance}

Optimal maintenance decision should be based on the actual deterioration conditions of the components. Amari et al. (2006) presented a generalized CBM model 
including a stochastic deterioration process, a set of MAs and optimal inspection schedule. Optimal maintenance decision is based on Markov Decision Processes (MDP). Jessop and Cook (2009) presented a modelbased decision support tool, combining three separate functional areas - a mission profile modeling tool, a system relational model, and a maintenance optimization module. The tool also incorporates fusion of multiple independent low-level indicators to predict overall system readiness, methodologies to account for the interactive effects of interconnected subsystems, and a risk-based optimization to select and schedule the optimal maintenance schedule.

CBM strategy for continuously deteriorating multicomponent systems is based on performing simultaneous MAs, and thus allowing cost savings. Gupta and Lawsirirat (2006) developed simulation-based optimization heuristic to obtain optimal MAs for a multicomponent system. Deterioration was modeled by a continuous-time jump diffusion model.

\subsection{Opportunity Based Maintenance}

Opportunity based maintenance (OBM) actions can save significant maintenance resources as they may reduce the number of maintenance interventions, especially when the set up cost of maintenance is high, as in offshore. For example, when MAs are planned and need to be carried out on offshore oil rig or on offshore wind farm in remote locations, getting to the equipment is costly.

Access to offshore drivetrains for maintenance and repair may be significantly restricted during periods of high wind speed and significant wave height, particularly during the winter. Such bad weather conditions lead to a short time-window for performing marine and maintenance operations on equipment which is difficult to access. Therefore, optimizing the best combination of MAs, at that point in time, is mandatory and OBM should be implemented.

OBM is based on PMAs, driven by the opportunity. These opportunistic MAs are precautionary since they are carried out prior to a failure, but are passive at the same time, as they wait to be scheduled, until the opportunity arises.

Opportunistic PMA is carried out by taking the advantage of the time when the equipment is not in use and the weather-window allows. PMA is carried out depending on other more critical maintenance actions, i.e. opportunity when repairing some more critical components of the same machinery/equipment. This may invoke replacing components, with significant residual lifetime, that in different circumstances would not be replaced.
Saranga (2004) used Genetic Algorithms (GAs) in deciding on opportunistic maintenance. Wang (2004) emphasised on opportunistic maintenance policies for multi-component systems.

Offshore modular structures, as mentioned in (5.1), may need shorter time-weather window to be maintained, since the marine operations with pre-assembled (onshore) modules are easier and faster.

\section{Conclusions}

As presented in this paper the maintenance of offshore machinery is different from maintenance of onshore machinery even though the type of machinery is often the same. The conditions offshore may reduce the accessibility to machinery compared to onshore installations. The reduced accessibility calls for a better knowledge about the state of the installed components to plan the maintenance actions. The time window for access may be limited so it is necessary to perform maintenance on parts that have not failed yet but are expected to fail before the next possible access. Compared to onshore installations the transportation offshore is often a substantial larger part of the expenses related to the maintenance. Therefore it may be economically beneficial to do maintenance on parts that have not yet failed if it can be done together with other maintenance work on the site. The methods presented in this paper can be useful in this planning work.

Much research has been done with respect to the use of wavelets and different variations in condition monitoring but still these methods are in limited use in industrial applications. In order for wavelets to become more popular in industry, work must be done to broaden the knowledge outside academia, but also the benefits of wavelets compared to FFT must become clear to practioners. One necessary step must be to include wavelet analysis as an option in commercially available vibration analyzers.

In the onshore wind energy industry there is a long tradition for gathering a large amount of data during the operation. So far these data have not in general been used proactive to estimate the remaining life of parts in the system. The data has mainly been used to find the cause of failure when the failure has already happened. The tradition for gathering data during operation must be continued when it comes to offshore wind equipment and it must also be incorporated in the equipment in the offshore oil \& gas industry. Traditionally it has not been easy in the oil \& gas business to convince a customer about the benefits of providing data back to the manufacturer. Therefore it is required to change the mindset in the administration and organisation in some parts of the industry. 
Further research and development of CBM in the oil \& gas industry is likely to be linked with the Integrated Operations (IOs) mindset. Offshore production operations in harsh environments call for a strong focus on technical condition, technical integrity and maintenance efficiency. By implementing the IOs, the maintenance management strategy may be robust and flexible. IOs philosophy is based on promoting work practices for utilizing competencies and mobilizing knowledge irrespective of disciplines, locations and company borders. IOs are based on effective utilizing real-time data by means of progressive information and communication technologies (ICT), in order to improve maintenance-related decisions and optimize work processes, Bye et al. (2010). Holst and Nystad (2007) presented a real application of new ICT, such as intelligent real-time information workspaces and 3D visualizations. These IOs allow production and process optimization, and thus improving maintenance planning and decision-making. Utne et al. (2012) presented an approach supporting the decision-maker in the selection of condition monitoring methods for production equipment. The Norwegian Oil Industry Association, OLF (2006), presented a study of several offshore oil fields, with focus on the value of IOs. Improved opportunity to monitor the equipment condition and performance automatically, constitutes an IOs value. The largest contributing factors to the potential value are reserve increase and accelerated production as a result of production optimisation. Stenvaag et al. (2008) shows that challenges with IOs are more related to organisation and competence than technology itself.

In many cases existing sensors and measuring equipment used for control purposes can be used for obtaining the data but the need for further instrumentation must be expected. In both industries it is also required to build up competences within analysis of the data describing the condition of the equipment.

\section{References}

Albizu, I., Zamora, I., Mazon, A., and Tapia, A. Techniques for online diagnosis of stator shorted turns in induction motors. Electric Power Components and Systems, 2006. 34(1):97-114. doi:10.1080/15325000691001359.

Amari, S., McLaughlin, L., and Pham, H. Costeffective condition-based maintenance using markov decision processes. In Proceedings Annual Reliability and Maintainability Symposium $R A M S^{\prime} 06$, volume 2. pages 464-469, 2006. doi:10.1109/RAMS.2006.1677417.

Ambarisha, V. and Parker, R. Nonlinear dynamics of planetary gears using analytical and finite element models. Journal of Sound and Vibration, 2007. 302(2):577-595. doi:10.1016/j.jsv.2006.11.028.

Antonino-Daviu, J., Riera-Guasp, M., Folch, J., and Palomares, M. Validation of a new method for the diagnosis of rotor bar failures via wavelet transform in industrial induction machines. IEEE Trans. Ind. Appl., 2006. 42(4):990-996. doi:10.1109/TIA.2006.876082.

Arthur, N. Development, implementation and application of a condition based maintenance assessment tool for the uk oil and gas industry. Int. Journal of COMADEM, 2005. 8(4):2-9.

Assaf, T., Henao, H., and Capolino, G. Simplified axial flux spectrum method to detect incipient stator inter-turn short-circuits in induction machine. In 2004 IEEE International Symposium on Industrial Electronics, volume 2. pages 815-819, 2004. doi:10.1109/ISIE.2004.1571918.

Bethel, N. Identifying motor defects through fault zone analysis. Iron and steel engineer, 1999. 76(4):64-67.

Bhushan, B. and Gupta, B. Handbook of Tribology: Materials, Coatings, and Surface Treatments. McGraw-Hill, 1991.

Blödt, M., Granjon, P., Raison, B., and Regnier, J. Fault detection, chapter 20: Mechanical fault detection in induction motor drives through stator current monitoring - Theory and application examples, pages 451-488. In-Teh, 2010.

Boashash, B. Time Frequency Signal Analysis and Processing - A Comprehensive Reference. Elsevier, 2003.

Briz, F., Degner, M., Garcia, P., and Bragado, D. Broken rotor bar detection in line-fed induction machines using complex wavelet analysis of startup transients. IEEE Trans. Ind. Appl., 2008. 44(3):760768. doi:10.1109/TIA.2008.921382.

Bye, R., Hansson, L., and Okstad, E. Implementing integrated operations in a mobile offshore production service provider. In SPE Intelligent Energy Conference and Exhibition 2010, volume 2. Society of Petroleum Engineers, pages 641-654, 2010. doi:10.2118/128504-MS.

Carter, S., Fisher, A., Goodall, P., Hinds, M., Lancaster, S., and Shore, S. Atomic spectrometry update: Industrial analysis: metals, chemicals and advanced materials. Journal of Analytical Atomic Spectrometry, 2010. 25(12):1808-1858. doi:10.1039/C005533F. 
Cash, M., Habetler, T., and Kliman, G. Insulation failure prediction in ac machines using line-neutral voltages. IEEE Transactions on Industry Applications, 1998. 34(6):1234-1239. doi:10.1109/28.738983.

Choux, M., Tyapin, I., and Hovland, G. Leakagedetection in blade pitch control systems for wind turbines. In Proc. the Annual Reliability and Maintainability Symposium. pages 1-7, Jan. 23-26, 2012, Nevada.

Dempsey, P. A comparison of vibration and oil debris gear damage detection methods applied to pitting damage. Wear, 2000.

Dempsey, P. Gear damage detection using oil debris analysis. Wear, 2001.

Ebersbach, S., Peng, Z., and Kessissoglou, N. The investigation of the condition and faults of a spur gearbox using vibration and wear debris analysis techniques. Wear, 2006. 260(1-2):16-24. doi:10.1016/j.wear.2004.12.028.

Edmonds, J., Resner, M., and Shkarlet, K. Detection of precursor wear debris in lubrication systems. In 2000 IEEE Aerospace Conference Proceedings, volume 6. pages 73-78, 2000. doi:10.1109/AERO.2000.877884.

Ellingssen, H., Liyanage, J., and Ruså, R. Smart integrated operations and maintenance solutions to manage offshore assets in north sea. In Proceedings of the 18th EuroMaintenace. MM Support GmbH, pages 319-324, 2006.

FAG. Rolling Bearings and their Contribution to the Progress of Technology. FAG Kugelfischer Georg Schäfer KGaA, 1986.

Flandrin, P. Time-Frequency/Time-Scale Analysis. Academic Press, 1999.

Foster, K. Rolling bearings as crime scenes. Pumps $\mathscr{E}$ Systems Magazine, 2009. 3.

Gao, J., Zhang, P., Liu, B., and Xie, Z. An integrated fault diagnosis method of gearboxes using oil analysis and vibration analysis. In 8th International Conference on Electronic Measurement and Instruments ICEMI '0\% pages 371-374, 2007. doi:10.1109/ICEMI.2007.4350932.

Gao, Z., Habetler, T., Harley, R., and Colby, R. A sensorless adaptive stator winding temperature estimator for mains-fed induction machines with continuous-operation periodic duty cycles. IEEE Transactions on Industry Applications, 2008. 44(5):1533-1542. doi:10.1109/TIA.2008.2002208.
Garnero, M.-A., Beaudouin, F., and Delbos, J.-P. Optimization of bearing-inspection intervals. In Proc. Reliability and Maintainability Symposium. pages 332-338, 1998. doi:10.1109/RAMS.1998.653801.

Gentile, G., Meo, S., and Ometto, A. Induction motor current signature analysis to diagnostics, of stator short circuits. In 4th IEEE International Symposium on Diagnostics for Electric Machines, Power Electronics and Drives (SDEMPED) 2003, volume 2. pages 47-51, 2003. doi:10.1109/DEMPED.2003.1234545.

Grubic, S., Aller, J., Lu, B., and Habetler, T. Survey of testing and monitoring methods for stator insulation systems in induction machines. Proc. of 2008 Intl. Conf. on Condition Monitoring and Diagnostics, 2008. pages 196-203. doi:10.1109/CMD.2008.4580262.

Guo, Y. and Parker, R. Dynamic modeling and analysis of a spur planetary gear involving tooth wedging and bearing clearance nonlinearity. European Journal of Mechanics A/Solids, 2010. 29(6):1-12 (In Press). doi:10.1016/j.euromechsol.2010.05.001.

Gupta, A. and Lawsirirat, C. Strategically optimum maintenance of monitoring-enabled multicomponent systems using continuous-time jump deterioration models. Journal of Quality in Maintenance Engineering, 2006. 12(3):306-329. doi:10.1108/13552510610685138.

Hansen, A., Rasmussen, F., and Larsen, T. Gearbox loads caused by double contact simulated with hawc2. In European Wind Energy Conference and Exhibition, Poland. 2010.

Holst, B. and Nystad, E. Oil \& gas offshore/onshore integrated operations - introducing the brage $2010+$ project. In 2007 IEEE 8th HFPP and HPRCT 13th Annual Meeting. pages 357-359, 2007. doi:10.1109/HFPP.2007.4413233.

J. Geiman, B. I. C. Dc step-voltage and surge testing of motors. Maintenance Technology magazine, 2007. 3:1-7. URL http://www.mt-online.com.

Jardine, A., Lin, D., and Banjevic, D. A review on machinery diagnostics and prognostics implementing condition-based maintenance. Mechanical Systems and Signal Processing, 2006. 20(7):1483-1510. doi:10.1016/j.ymssp.2005.09.012.

Jessop, S. and Cook, T. A model-based mission planning and decision support tool. In Proceedings of the ASME Turbo Expo, volume 4. pages 991-999, 2009. doi:10.1115/GT2009-60215. 
Jones, B., I.Jenkinson, Z.Yang, and J.Wang. The use of bayesian network modelling for maintenance planning in a manufacturing industry. Reliability Engineering and System Safety, 2010. 95(3):267-277. doi:10.1016/j.ress.2009.10.007.

Junsheng, C., Dejie, Y., and Yu, Y. Timeenergy density analysis based on wavelet transforms. NDT and E International, 2005. 38(7):569-572. doi:10.1016/j.ndteint.2005.02.002.

Kar, C. and Mohanty, A. Vibration and current transient monitoring for gearbox fault detection using multiresolution fourier transform. Journal of Sound and Vibration, 2008. 311(1-2):109-132. doi:10.1016/j.jsv.2007.08.023.

Kawazoe, T. and Ura, A. Corrosive wear testing of metals in seawater. In ASTM Special Technical Publication, 1404. pages 296-305, 2001.

Kim, H. and Ju, Y. Comparison of off-line and online partial discharge for large motors. In Conference Record of the 2002 IEEE International Symposium on Electrical Insulation. pages 27-30, 2002. doi:10.1109/ELINSL.2002.995873.

Kothamasu, R., Huang, S., and Verduin, W. System health monitoring and prognostics - a review of current paradigms and practices. International Journal of Advanced Manufacturing Technology, 2006. 28(9):1012-1024. doi:10.1007/s00170-004-2131-6.

Landolt, D. Electrochemical and materials aspects of tribocorrosion systems. Journal of Physics D: Applied Physics, 2006. 39(15):3121-3127. doi:10.1088/0022-3727/39/15/S01.

Landolt, D. Corrosion and Surface Chemistry of Metals, chapter 6: Passivity of Metals, pages 227-274. EPFL Press, 2007.

Larsen, T., Thomsen, K., and Rasmussen, F. Dynamics of a wind turbine planetary gear stage. Technical Report Risoe-I-2112, Risoe National Laboratory, Denmark., 2003.

Lee, S., Habetler, T., Harley, R., and Gritter, D. An evaluation of model-based stator resistance estimation for induction motor stator winding temperature monitoring. IEEE Transactions on Energy Conversion, 2002. 17(1):7-15. doi:10.1109/60.986431.

Lee, S., Tallam, R., and Habetler, T. A robust, on-line turn fault detection technique for induction machines based on monitoring the sequence component impedance matrix. IEEE Transactions on Power Electronics, 2003. 18(3):865-872. doi:10.1109/TPEL.2003.810848.
Lee, S., Yang, J., Younsi, K., and Bharadwaj, R. An online groundwall and phase-to-phase insulation quality assessment technique for acmachine stator windings. IEEE Transactions on Industry Applications, 2006. 42(4):946-957. doi:10.1109/TIA.2006.876077.

Lin, J. and Parker, R. Analytical characterization of the unique properties of planetary gear free vibration. Journal of Vibration and Acoustics, 1999. 121(3):319-321. doi:10.1115/1.2893982.

Lin, J. and Parker, R. Planetary gear parametric instability caused by mesh stiffness variation. Journal of Sound and Vibration, 2002. 249(1):129-145. doi:10.1006/jsvi.2001.3848.

Lin, J., Zuo, M., and Fyfe, K. Mechanical fault detection based on the wavelet de-noising technique. Journal of Vibration and Acoustics, 2004. 126(2):916. doi:10.1016/j.ymssp.2004.06.001.

Lin, Y., Hsu, A., and Rajamani, R. A simulation model for field service with condition-based maintenance. In Proceedings of the 2002 Winter Simulation Conference, volume 2. pages 1885-1890, 2002.

Liyanage, J. Complex System Maintenance Handbook, chapter 24: Integrated e-Operations-e-Maintenance: Applications in North Sea Offshore Assets, pages 585-609. Springer Series in Reliability Engineering, 2008. doi:10.1007/978-1-84800-011-7_24.

Loutridis, S. Instantaneous energy density as a feature for gear fault detection. Mechanical Systems and Signal Processing, 2006. 20(5):1239-1253. doi:10.1016/j.ymssp.2004.12.001.

Lu, B., Habetler, T., and Harley, R. A survey of efficiency estimation methods of inservice induction motors. IEEE Transactions on Industry Applications, 2006. 42(4):924-933. doi:10.1109/TIA.2006.876065.

Mendel, E., Rauber, T., ao, F. V., and Batista, R. Rolling element bearing fault diagnosis in rotating machines of oil extraction rigs. In Proceedings of 17th European Signal Processing Conference (EUSIPCO 2009). Glasgow, Scotland, pages 319-324, 2009.

Mischler, S. and Ponthiaux, P. A round robin on combined electrochemical and friction tests on alumina/stainless steel contacts in sulphuric acid. Wear, 2001. 248(1-2):211-225. doi:10.1016/S00431648(00)00559-7.

Mobius. Vibration Training Course Book - Category II, chapter 14: Diagnosing Misalignment. Mobius Institute, 2008. 
Murali, S., Xia, X., Jagtiani, A., Carletta, J., and Zhe, J. A microfluidic device for wear detection in lubricants. In ASME Conf. Proc., ASME 2008 International Mechanical Engineering Congress and Exposition (IMECE2008), volume 13. pages 859-863, 2008. doi:10.1115/IMECE2008-66768.

Musial, W., Butterfield, S., and McNiff, B. Improving wind turbine gearbox reliability. In Proceedings of 2007 European Wind Energy Conference. pages 1$10,2007$.

Myshkin, N., Markova, L., Semenyuk, M., Kong, H., Han, H., and Yoon, E. Wear monitoring based on the analysis of lubricant contamination by optical ferroanalyzer. Wear, 2003. 255(7-12):1270-1275. doi:10.1016/S0043-1648(03)00175-3.

Nandi, S., Toliyat, H., and Li, X. Condition monitoring and fault diagnosis of electrical motors-a review. IEEE Trans. Energy Convers., 2005. 20(4):719-729. doi:10.1109/TEC.2005.847955.

NEMA. NEMA MG 1 - Motors and Generators. National Electrical Manufacturers Association (NEMA), 2010.

Norton, R. Machine Design - An Integrated Approach, 3rd ed. Pearson-Prentice Hall, 2006.

von der Ohe, C., Johnsen, R., and Espallargas, N. Modeling the multi-degradation mechanisms of combined tribocorrosion interacting with static and cyclic loaded surfaces of passive metals exposed to seawater. Wear, 2010. 269(7-8):607-616. doi:10.1016/j.wear.2010.06.010.

OLF. Potential value of integrated operations on the norwegian shelf. Technical report, The Norwegian Oil Industry Association (OLF), 2006.

Palin-Luc, T., Perez-Mora, R., Bathias, C., Dominguez, G., Paris, P., and Arana, J. Fatigue crack initiation and growth on a steel in the very high cycle regime with sea water corrosion. Engineering Fracture Mechanics, 2010. 77(11):19531962. doi:10.1016/j.engfracmech.2010.02.015.

Peng, Z. and Chu, F. Application of the wavelet transform in machine condition monitoring and fault diagnostics: A review with bibliography. Mechanical Systems and Signal Processing, 2004. 18(2):199-221. doi:10.1016/S0888-3270(03)00075-X.

Peng, Z. and Kessissoglou, N. An integrated approach to fault diagnosis of machinery using wear debris and vibration analysis. Wear, 2003. 255(7-12):12211232. doi:10.1016/S0043-1648(03)00098-X.
Peng, Z., Kessissoglou, N., and Cox, M. A study of the effect of contaminant particles in lubricants using wear debris and vibration condition monitoring techniques. Wear, 2005. 258(11-12):1651-1662. doi:10.1016/j.wear.2004.11.020.

Piotrowski, J. Shaft Alignment Handbook. Taylor \& Francis, 2007.

Raadnui, S. and Kleesuwan, S. Low cost condition monitoring sensor for used oil analysis. Wear, 2005. 259(7-12):1502-1506. doi:10.1016/j.wear.2004.11.009.

Rasmussen, F., Thomsen, K., and Larsen, T. The gearbox problem revisited. Fact Sheet AED-RB-17 (EN). Risoe National Laboratory, Denmark., 2004.

Reichard, K., Dyke, M. V., and Maynard, K. Application of sensor fusion and signal classification techniques in a distributed machinery condition monitoring system. In Proceedings of SPIE - The International Society for Optical Engineering, volume 4051. Orlando, FL, USA, pages 329-336, 2000.

Ribrant, J. and Bertling, L. Survey of failures in wind power systems with focus on swedish wind power plants during 1997-2005. IEEE Transactions on Energy Conversion, 2007. 22(1):167-173. doi:10.1109/TEC.2006.889614.

Riera-Guasp, M., Antonino-Daviu, J., Roger-Folch, J., and Palomares, M. The use of the wavelet approximation signal as a tool for the diagnosis of rotor bar failures. IEEE Trans. Ind. Appl., 2008. 44(3):716726. doi:10.1109/TIA.2008.921432.

Rigdon, S. and Basu, A. Statistical Methods for the Reliability of Repairable Systems. Wiley, 2000.

Rodriguez, L., Garcia, E., Morant, F., Correcher, A., and Quiles, E. Application of latent nestling method using colored petri nets for the fault diagnosis in the wind turbine subsets. In Proc. 2008 IEEE Int. Conf. Emerging Technologies and Factory Automation. pages 767-773, 2008. doi:10.1109/ETFA.2008.4638486.

Roylance, B., Williams, J., and Dwyer-Joyce, R. Wear debris and associated wear phenomena-fundamental research and practice. In Proceedings of the Institution of Mechanical Engineers, Part J: Journal of Engineering Tribology, volume 214. pages 79-105, 2000. doi:10.1243/1350650001543025.

Saranga, H. Opportunistic maintenance using genetic algorithms. Journal of Quality in Maintenance Engineering, 2004. 10(1):66-74. doi:10.1108/13552510410526884. 
Sasaki, K. and Bursteina, G. Observation of a threshold impact energy required to cause passive film rupture during slurry erosion of stainless steel. Philosophical Magazine Letters, 2000. 80(7):489-493. doi:10.1080/09500830050057198.

Siddique, A., Yadava, G., and B.Singh. A review of stator fault monitoring techniques of induction motors. IEEE Transactions on Energy Conversion, 2005. 20(1):106-114. doi:10.1109/TEC.2004.837304.

Spinato, F., Tavner, P., van Bussel, G., and Koutoulakos, E. Reliability of wind turbine subassemblies. IET Renewable Power Generation, 2009. 3(4):387-401. doi:10.1049/iet-rpg.2008.0060.

SrinivasaPai, P., Mathew, M., Stack, M., and Rocha, L. Some thoughts on neural network modelling of microabrasion-corrosion processes. Tribology International, 2008. 41(7):672-681. doi:10.1016/j.triboint.2007.11.015.

Stenvaag, S., Lindrupsen, T., Bye, R., and sters, T. Integrated operations - a key enabler to operational excellence in maintenance management of fpsos. In SPE - Intelligent Energy Conference and Exhibition: Intelligent Energy 2008, volume 2. Society of Petroleum Engineers, pages 939-951, 2008. doi:10.2118/112227-MS.

Stone, G. Advancements during the past quarter century in on-line monitoring of motor and generator winding insulation. IEEE Transactions on Dielectrics and Electrical Insulation, 2002. 9(5):746751. doi:10.1109/TDEI.2002.1038661.

Stone, G. Recent important changes in ieee motor and generator winding insulation diagnostic testing standards. IEEE Transactions on Industry Applications, 2005. 41(1):91-100. doi:10.1109/TIA.2004.840977.

Stone, G., Boulter, E., Culbert, I., and Dhirani, H. Electrical insulation for rotating machines: Design, Evaluation, Aging, Testing, and Repair. Wiley - Interscience, IEEE Press - Series on Power Engineering, 2004.

Stone, G. and Kapler, J. Stator winding monitoring. IEEE Industry Applications Magazine, 1998. 4(5):15-20. doi:10.1109/2943.715501.

Tallam, R., Habetler, T., and Harley, R. Transient model for induction machines with stator winding turn faults. IEEE Transactions on Industry Applications, 2002. 38(3):632-637. doi:10.1109/TIA.2002.1003411.
Tan, C., Irving, P., and Mba, D. Diagnostics and prognostics with acoustic emission, vibration and spectrometric oil analysis for spur gears - a comparative study. Insight - Non-Destructive Testing and Condition Monitoring, 2005. 47(8):478-480. doi:10.1784/insi.2005.47.8.478.

Tang, B., Liu, W., and Song, T. Wind turbine fault diagnosis based on Morlet wavelet transformation and Wigner-Ville distribution. Renewable Energy, 2010. 35(12):2862-2866. doi:10.1016/j.renene.2010.05.012.

Tavner, P., van Bussel, G., and Spinato, F. Machine and converter reliabilities in wind turbines. In Proceedings of 3rd International IEEE Conference Power Electronics Machines and Drives. pages 127130, 2006.

Tavner, P., Xiang, J., and Spinato, F. Reliability analysis for wind turbines. Wind Energy, 2007. 10(1):118. doi:10.1002/we.204.

Thomson, W. and Fenger, M. Current signature analysis to detect induction motor faults. IEEE Industry Applications Magazine, 2001. 7(4):26-34. doi:10.1109/2943.930988.

Thorsen, O. and Dalva, M. A survey of faults on induction motors in offshore oil industry, petrochemical industry, gas terminals, and oil refineries. IEEE Trans. Ind. Appl., 1995. 31(5):1186-1196. doi:10.1109/28.464536.

Troyer, D. and Williamson, M. Effective integration of vibration analysis and oil analysis. In Proceedings of the International Conference on Condition Monitoring. pages 411-420, 1999.

Trutt, F., Sottile, J., and Kohler, J. Condition monitoring of induction motor stator windings using electrically excited vibrations. In Conference Record of the Industry Applications Conference, 2002, 37th IAS Annual Meeting, volume 4. pages 2301-2305, 2002. doi:10.1109/IAS.2002.1042767.

Tyapin, I., Hovland, G., and Jorde, J. Comparison of markov theory and monte carlo simulations for analysis of marine operations related to installation of an offshore wind turbine. In Proc. of COMADEM 2011, Stavanger, Norway. pages 1071-1081, 2011.

Utne, I., Brurok, T., and Rdseth, H. A structured approach to improved condition monitoring. Journal of Loss Prevention in the Process Industries, 2012. 25(3):478-488. doi:10.1016/j.jlp.2011.12.004.

Wang, H. A survey of maintenance policies of deteriorating systems. European Journal of Operational 
Research, 2004. 139(3):469-489. doi:10.1016/S03772217(01)00197-7.

Watson, S., Xiang, B., Yang, W., Tavner, P., and Crabtree, C. Condition monitoring of the power output of wind turbine generators using wavelets. IEEE Transactions on Energy Conversion, 2010. 25(3):715-721. doi:10.1109/TEC.2010.2040083.

Werynski, P., Roger, D., Corton, R., and Brudny, J. Proposition of a new method for in-service monitoring of the aging of stator winding insulation in ac motors. IEEE Transactions on Energy Conversion, 2006. 21(3):673-681. doi:10.1109/TEC.2006.875465.

Wiedenbrug, E., Frey, G., and Wilson, J. Impulse testing and turn insulation deterioration in electric motors. In Proceedings of the IEEE Pulp and Paper Industry Technical Conference 2003. pages 50-55, 2003. doi:10.1109/PAPCON.2003.1216899.

Wiggelinkhuizen, E., Verbruggen, T., Braam, H., Rademakers, L., Xiang, J. P., and Watson, S. Assessment of condition monitoring techniques for offshore wind farms. J. Solar Energy Eng.Trans. ASME, 2008. 130(3):031004 (9 pages). doi:10.1115/1.2931512.

Wood, R., Bahaj, A., Turnock, S., Wang, L., and Evans, M. Tribological design constraints of marine renewable energy systems. Philosophical Transactions of the Royal Society A: Mathematical, Physical and Engineering Sciences, 2010. 368(1929):48074827. doi:10.1098/rsta.2010.0192.

Wright, J. Lubricating electric motors. Machinery Lubrication Magazine, 2008.

Yang, W. and Ren, X. Detecting impulses in mechanical signals by wavelets. EURASIP Journal on Applied Signal Processing, 2004. 2004(8):1156-1162. doi:10.1155/S1110865704311091.

Zhang, J. and Drinkwater, B. Monitoring of lubricant film failure in a ball bearing using ultrasound. Journal of Tribology, 2006. 128(3):612-618. doi:10.1115/1.2197848.

Zhang, Z., Ren, Z., and Huang, W. A novel detection method of motor broken rotor bars based on wavelet ridge. IEEE Trans. Energy Convers., 2003. 18(3):417-423. doi:10.1109/TEC.2003.815851.

Zipp, K. Intelligent vibration monitoring for wind plants. Windpower Engineering, 2010. 